JOURNAL OF

HORTICULTURAL

SCIENCES
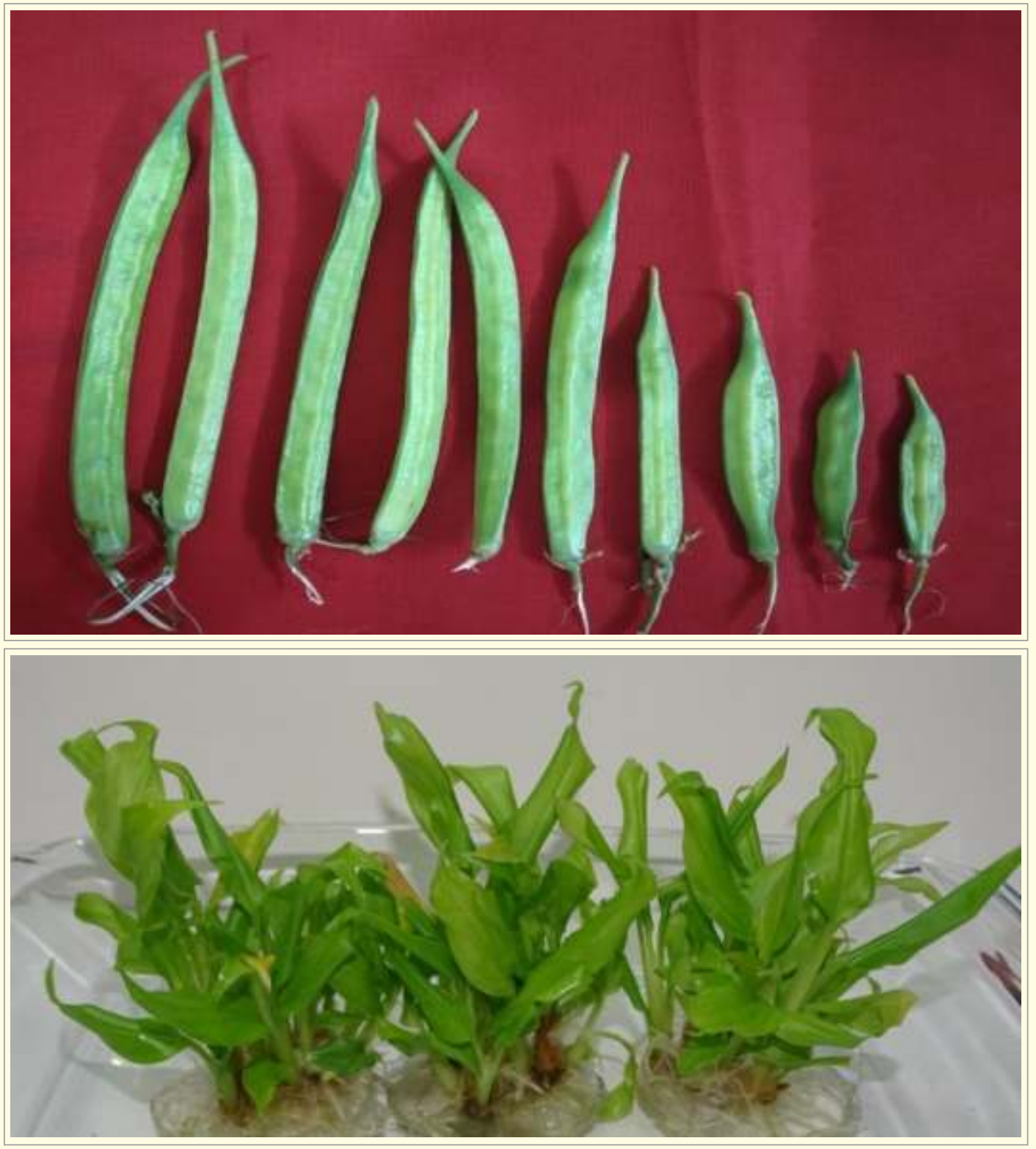

Society for Promotion of Horticulture

ICAR - Indian Institute of Horticultural Research, Bengaluru - 560089 


\section{JOURNAL OF HORTICULTURAL SCIENCES}

\section{ONTENTS}

\section{In this Issue}

\section{Review}

Moringa (Moringa oleifera L.): An underutilized and traditionally valued

tree holding remarkable potential

Jattan M., Kumari N., Raj Kumar, Kumar A., Rani B., Phogat D.S.,

Kumar, S. and Kumar, P.

\section{Original Research in Papers}

Characterization and evaluation of mountain sweet thorn

(Flacourtia montana J. Grah) collections

Tripathi P.C., Ganeshan S., Radhika V. and Shetti D.L.

Optimization of methodology for the extraction of polyphenolic compounds

with antioxidant potential and á-glucosidase inhibitory activity from jamun

(Syzygium cumini L.) seeds

Arivalagan M., Priyanka D.R. and Rekha A.

Genetic variability studies in amaranthus (Amaranthus spp.)

Agadi A.H., Kolakar S., Lakshmana D., Nadukeri S. and Hanumanthappa M.

Morpho-physiological parameters associated with chlorosis resistance to

iron deficiency and their effect on yield and related attributes in potato

(Solanum tuberosum L.)

Challam C., Dutt S., Sharma J., Raveendran M. and Sudhakar D.

Responses of different Okra (Abelmoschus esculentus) cultivars to water

deficit conditions

Ayub Q., Khan S.M., Hussain I., Naveed K., Ali S., Mehmood A., Khan M.J., Haq N.U., Shehzad Q.

Induced variability for yield and its attributing traits in cluster bean

[Cyamopsis tetragonoloba (L. ) Taub] through gamma irradiation

Lavanya H.N., Mishra S., Sood M., Aghora T.S., Anjanappa M., Rao V.K. and Reddy A.B.

In vitro multiplication protocol for Curcuma mangga : Studies on carbon,

Waman A.A., Bohra P., Karthika Devi R. and Pixy J. 
Effect of fungicide and essential oils amended wax coating on quality and shelf life of sweet orange (Citrus sinensis Osbeck)

Bhandari M., Bhandari N. and Dhital M.

Post-harvest quality and quantification of betalains, phenolic compounds and antioxidant activity in fruits of three cultivars of prickly pear

(Opuntia ficus-indica L. Mill)

Gonzalez F.P.H., Saucedo V.C., Guerra R.D., Suarez E.J., Soto H.R.M. Lopez J.A.,

Garcia C.E. and Hernandez R.G.

Soil microbial community dynamics as influenced by integrated nutrient management practices in sweet basil (Ocimum basilicum L.) cultivation Baraa AL-Mansour and D. Kalaivanan

Effect of spectral manipulation and seasonal variations on cut foliage production and quality of Philodendron (Philodendron 'Xanadu')

Sujatha A. Nair, Laxman R.H. and Sangama

\section{Short Communications}

Studies on mutagenic sensitivity of seeds of pummelo (Citrus maxima Merr.)

Sankaran M., Kalaivanan D. and Sunil Gowda D.C.

Isolation and characterization of microsatellite markers from

Garcinia indica and cross species amplification

Ravishankar K.V., Vasudeva R., Hemanth B., Nischita P., Sthapit B.R.,

Parthasarathy V.A. and Rao V.R. 


\title{
Morpho-physiological parameters associated with chlorosis resistance to iron deficiency and their effect on yield and related attributes in potato (Solanum tuberosum L.)
}

\author{
Challam C. ${ }^{* 1}$, Dutt S. ${ }^{1}$, Sharma J. ${ }^{1}$, Raveendran M. ${ }^{2}$ and Sudhakar D. ${ }^{2}$ \\ ${ }^{1}$ ICAR-Central Potato Research Institute, Shimla, Himachal Pradesh - 171001 \\ ${ }^{2}$ Department of Plant Biotechnology, CPMB\&B, Tamil Nadu Agricultural University, Coimbatore - 641003 \\ *Corresponding author Email: clarissachallam@gmail.com
}

\begin{abstract}
The aim of the study was to assess genotypical differences over different stages for morphophysiological parameters associated with iron (Fe) deficiency and their effect on yield. The factorial pot experiment was comprised of two major factors, i) soil-Fe status of natural vertisol [Fe-sufficient and Fe-deficient soils], and ii) genotypes [CP-3443, CP- 4105, CP-3486 and CP-4069] with differential iron-induced deficiency chlorosis (IDC) response. Data were recorded and associations between different traits were estimated. Under Fe-deficient soil, tolerant genotype (CP-3443) recorded significantly higher chlorophyll content, peroxidase activity in leaves and better yield compared to susceptible genotypes which verified usefulness as IDC tolerant potato genotypes characteristics.
\end{abstract}

Key words: Correlation, Iron-deficiency chlorosis, Morpho-physiological parameters; Potato and Yield

\section{INDRODUCTION}

Iron $(\mathrm{Fe})$, one of the essential micronutrients for the growth and development of all living organisms, its deficiency is a serious problem in both agriculture and human nutrition. Iron is considerably less soluble in soils with a $\mathrm{pH}$ value of 8 than $\mathrm{Zn}$ or $\mathrm{Mn}$; thus, inorganic Fe makes relatively little contribution to the Fe nutrition of plants in calcareous soils (Singh et al., 2004). Fe level varies with the type and depth of the soil, ranging from $0.2 \%$ to $55 \%(20,000$ to 550,000 $\mathrm{mg} \mathrm{kg} 1$ ), and the highest concentration is found at 2$15 \mathrm{~cm}$ (Mahender et al., 2019). For instance, the total Fe content in Indian soil ranges from $0.4 \%$ to $27.3 \%$ $(40,000$ to $273,000 \mathrm{mg} \mathrm{kg} 1)$, but that accessible to the plant is extremely variable, from 0.36 to $174 \mathrm{mg}$, which depends on the soil, plant, and environmental factors (Mahender et al., 2019). Calcareous soils may contain high total $\mathrm{Fe}$ levels but are not accessible to the plants, because iron forms water-insoluble hydroxides and oxides, and/or Fe carbonatesbicarbonates. Thus, high bicarbonate ion concentration leads to iron-induced deficiency chlorosis (IDC) by suppressing iron uptake and/or translocation in plants (Li-Xuan et al., 2005).
Potato (Solanum tuberosum L.) is a multipurpose crop and is the $4^{\text {th }}$ most important crop contributing to the world's food requirement next to rice, wheat and maize with a global production of 388 MMT during 2017 (FAOSTAT, 2019). Potato crop is sensitive to non-optimal iron content in the substrate and marked decreases in tuber quality and yield were reported with reduced biomass, chlorophyll concentrations and alterations in enzyme activities (peroxidase, catalase and acid phosphatase) under Fedeficient stress (Chatterjee et al., 2006). Susceptibility to $\mathrm{Fe}$ chlorosis is based on a plant's response to $\mathrm{Fe}$ deficiency stress and this is genetically regulated (Simko et al., 2008). IDC response is usually assessed by chlorophyll content in potato (Chatterjee et al., 2006) and also other legumes like soybean, dry bean etc (Samdur et al., 1999; Samdur et al., 2000). Higher chlorophyll content indicates a lower occurrence of chlorosis in leaves. Iron deficiency was also found to decrease the production of oxidative stress-related enzymes such as peroxidase in several plant species and is due to less Fe concentrations in Fe-deficient leaves (M'sehli et al., 2014). 
Developing micronutrient-efficient genotypes can be a quick, fast and successful way to resolve soil micronutrient disorders and improve human health. In previous studies, we have screened genotypes at seedling stage with the intent to identify IDC tolerant potato genotypes. IDC tolerant genotypes had registered a significantly lower reduction in plant height, SPAD value, chlorophyll content, and peroxidase level under Fe-deficient condition. However, the association of morpho-physiological parameters under iron deficiency and their effect on yield in potato genotypes has not been examined. Given that genetic variability for IDC responses exist among potato genotypes. The objective of the study was to access genotypic differences for different morpho-physiological and biochemical parameters associated with IDC tolerance across growth stages and their yield under natural vertisol (normal and calcareous) soils using pot studies.

\section{MATERIALS AND METHODS}

Based on our earlier study (Challam et al., 2021), 15 potato genotypes were evaluated for responses to Fe deficiency stress under controlled aeroponic condition. Potato genotypes with differential IDC response (tolerant: CP-3443; moderately tolerant: CP- 4105; moderately susceptible: CP-3486 and susceptible: CP-4069) were further selected for the pot experiment under net house condition at ICARCentral Potato Research Institute, Regional Station, Shillong. Two soil type viz. Fe- sufficient and Fedeficient were collected from two different sites Upper Shillong $\left(25.54^{\circ} \mathrm{N}, 91.85^{\circ} \mathrm{E}\right)$ and Nongrah $\left(25.57^{\circ} \mathrm{N}, 91.93^{\circ} \mathrm{E}\right)$, respectively. Soil samples were collected from identified sites by using hand auger at the soil depths of $0-30 \mathrm{~cm}$ by adopting random sampling procedure as described by Kalra, 1988. In vitro propagated potato plantlets of the genotypes were planted in twenty-five-centimetre plastic pots were filled with vertisol soils ( $\mathrm{pH}: 4.3)$ having available Fe $7.25 \mathrm{mg} / \mathrm{Kg}$ (DTPA extractable) for $\mathrm{Fe}$ sufficient plants whereas Fe deficient plants were filled with calcareous vertisol soil (pH: 8.6) having available Fe $4.53 \mathrm{mg} / \mathrm{Kg}$ (DTPA extractable) (Table 1). All the major nutrients $(\mathrm{N}, \mathrm{P}, \mathrm{K})$ were supplied in the form of urea, diammonium phosphate, and muriate of potash fertilizers according to the prescribed dosage. Micronutrients such as $\mathrm{Zn}, \mathrm{Mn}$ and $\mathrm{Mg}$ were added in the form of sulphates to avoid the difficulty of concurrent symptoms of Fe deficiency. One-month old in vitro plantlets were transplanted into pots and were irrigated with de-ionized water as and when required. The experimental design was conducted with completely randomized design with four replication per treatment. Throughout the duration of the experiment, all the necessary management practices including pest and diseases control were carried out to ensure good growth and development. Plant growth parameters associated with Fe deficiency were assessed as described below. All the parameters were recorded at different intervals 30,60,90 and 120 days (harvest) after planting. The morpho-physiological and biochemical parameters such as plant height, number of main stems, number of leaves, chlorophyll content and peroxidase were recorded across the growth stages. Number and weight of tubers along with root: shoot ratio and were estimated after harvest stage.

All the parameters were recorded at different intervals 30, 60, 90 and 120 days after planting. The growth parameters such as plant height (round level to the tip of the last opened leaf), total number of stem and number of leaves were recorded. Physio-biochemical parameters viz. SPAD values (Boodi et al., 2016), chlorophyll and peroxidise (Chatterjee and Chatterjee, 2003) were measured across the growth stages. To obtain tuber yield plants were maintained till maturity in each treatment. Number and weight of tubers along with root: shoot ratio were estimated after harvest stage.

\section{Table 1: Properties of the initial soil used for pot experiment}

\begin{tabular}{|l|c|c|}
\hline Soil properties & $\begin{array}{c}\text { Fe-sufficient } \\
\text { soil }\end{array}$ & $\begin{array}{c}\text { Fe-deficient } \\
\text { soil }\end{array}$ \\
\hline Soil $\mathrm{pH}$ & 5.73 & 8.13 \\
\hline $\begin{array}{l}\text { Electrical conductivity } \\
\text { (dS m-1) }\end{array}$ & 0.31 & 0.23 \\
\hline Organic carbon (\%) & 1.26 & 1.67 \\
\hline Free CaCO3 (\%) & 5.70 & 10.6 \\
\hline $\begin{array}{l}\text { DTPA extractable-Fe } \\
\text { (mg kg-1) }\end{array}$ & 17.5 & 4.53 \\
\hline
\end{tabular}


Mean squares for IDC tolerant associated traits, yield and it related traits were estimated with the aid of AGRES statistical package. Comparison between the treatments was made by using common least significant difference at $(\mathrm{P}=0.05)$. Pearson's correlation coefficient between IDC tolerance associated traits across four stages, yield and it related traits were estimated for Fe-deficient soils and significance was tested $(\mathrm{P}=0.05$ and $0.01)$.

\section{RESULTS AND DISCUSSION}

\section{Morpho-physiological parameters}

Growth and development in plants are a consequence of excellent coordination of several processes operating at different growing phases of plant. Plant height, total number of stem and number of leaves are important morphological character representing vigour of the plant during the growth and development. These growth indicators were measured periodically during the crop period. Being an essential micronutrient, Fe promoted the growth of all potato genotypes when grown at Fe-sufficient soil. Significant difference was observed for plant height, total main stem and number of leaves between the genotypes under different soil condition at all the phenological stages viz., 30, 60, 90 and at harvest stage. The comparison between Fe-sufficient and Fe-deficient soil showed significant reduction in plant height and number of stems under Fe-deficient soil (Table 2). This reduction may be attributed to reduced cell division, meristematic activity in apical tissue, expansion of cell and formation of new cell wall under Fe starvations (Boodi et al., 2016). The reduction of plant height during stress can serve an advantageous purpose for plants to reduce transportation distances, which can help to efficiently distribute water, nutrients and assimilates in plants (Aliche et al., 2020). On the contrary, number of leaves was found to increase as many side shoots were observed as a result of Fedeficiency in Fe-deficient soil. Tolerant genotype CP-3443 showed least reduction in number of leaves i.e., a greater number of leaves compared to other genotypes although lesser in plant height. Boamponsem et al., (2017) made a similar observation under Fe-deficient conditions, Feefficient potatoes have a greater number of leaves due to shorter internodal distance and stem height. This may be influenced by genetic characteristics of genotype related to its ability to grow better and give the higher yield.

Chlorophylls, the plant pigments responsible for harvesting solar energy and converting into required chemical energy, exhibit a differential pattern in their accumulation in crop plants. Gradual increase in chlorophyll was observed from 30 to 90 days, but decline there onwards until harvest was evident for all the genotypes in Fe-deficient soils. The higher chlorophyll content in plants under $\mathrm{Fe}$ deficient soil for initial growth periods could be attributed to the possible acquisition of appreciable Fe stores during prior growth of in vitro plants on sufficient $\mathrm{Fe}$ medium and available $\mathrm{Fe}$ in soil. Hence, plants were capable of sustaining chlorophyll biosynthesis during early stages on exposure to low Fe supplies. After 90 days, however, the plants could not acquire sufficient $\mathrm{Fe}$ from deficient soil led to inhibition of chlorophyll synthesis. The interaction effect was found significant across the growth stage in chlorophyll ( $\mathrm{a}, \mathrm{b}$ and total) (Table 2). Chlorophyll (a, b, and total) were significantly higher among tolerant followed by moderately tolerant genotype, but susceptible ones showed significantly lesser content during all the four crop growth stages under Fe-deficient soils (Table 2). The ability to absorb Fe from the soil under Fe-deficient soil as evident in tolerant and moderately tolerant genotypes helps to produce more chlorophyll pigments, since most of the leaf iron is found in chloroplast, primarily in photosynthetic electron transport chain complexes that comprise about 60 $\%$ of the total content of the leaf iron (Terry and Abadia, 1986).

Peroxidase (POD) content underwent a significant increase from $30,60,90$ days but decline there onwards until 120 days was evident for all the genotypes under both soil conditions. However, Fedeficient induced a noticeable decrease in the values of peroxidase in comparison to the Fe-sufficient condition (Table 2). The POD is a heme-containing enzyme and therefore its activity and/or synthesis are probably affected by iron deficiency. In the current study, decreased POD activity under limited Fe supply 
Table 2 : Mean performance of potato genotypes for morpho-physiological parameters in Fe-sufficient and Fe-deficient soils across growth stages

\begin{tabular}{|c|c|c|c|c|c|c|c|c|c|c|c|c|}
\hline \multicolumn{2}{|c|}{ Time interval } & \multicolumn{2}{|c|}{30 days } & \multicolumn{2}{|c|}{60 days } & \multicolumn{2}{|c|}{90 days } & \multicolumn{2}{|c|}{$\begin{array}{c}120 \text { days } \\
\text { (Harvest stage) }\end{array}$} & \multicolumn{2}{|c|}{ Mean } & \multirow[t]{2}{*}{$\begin{array}{c}\text { Chang } \\
(\%)\end{array}$} \\
\hline Trait & Genotype & $\mathrm{C}$ & $\mathbf{T}$ & $\mathrm{C}$ & $T$ & C & $T$ & $\mathrm{C}$ & $T$ & C & $T$ & \\
\hline \multirow{4}{*}{$\begin{array}{l}\text { Plant } \\
\text { height } \\
\text { (cII) }\end{array}$} & CP-3486 & 26.3 & 21.8 & 35.6 & 29.3 & 48.9 & 45.9 & 58.8 & 50.9 & 42.4 & 36.97 & 13.4 \\
\hline & CP-4069 & 30.3 & 28.3 & 44.6 & 41.2 & 55.8 & 51.8 & 63.9 & 58.8 & 48.65 & 45.02 & 8.0 \\
\hline & CP-3443 & 28.5 & 23.3 & 40.9 & 38.9 & 52.9 & 48.4 & 60.6 & 54.6 & 45.72 & 41.30 & 9.9 \\
\hline & CP-4105 & 25.5 & 20.4 & 33.4 & 28.4 & 50.4 & 45.2 & 56.5 & 48.7 & 41.45 & 35.67 & 13.8 \\
\hline \multicolumn{2}{|l|}{ Mean } & \multicolumn{2}{|c|}{25.55} & \multicolumn{2}{|c|}{36.53} & \multicolumn{2}{|c|}{$\frac{1}{49.91}$} & \multicolumn{2}{|c|}{56.6} & & & \\
\hline \multicolumn{2}{|l|}{$\mathrm{LSD}^{\#}$} & $0.53^{* *}$ & $0.37^{* *}$ & $0.94^{* *}$ & $0.66^{* *}$ & $1.15^{* *}$ & $0.81^{* *}$ & $1.49 * *$ & $1.06^{* *}$ & & & \\
\hline \multicolumn{2}{|l|}{$\mathrm{C} \times \mathrm{T}^{\S}$} & \multicolumn{2}{|c|}{$0.748^{*}$} & \multicolumn{2}{|c|}{ NS } & & & & & & & \\
\hline & CP-3486 & 1.3 & 1.1 & 2.2 & 2.0 & 2.9 & 2.2 & 3.3 & 2.5 & 2.42 & 1.95 & 24.2 \\
\hline Total & CP-4069 & 1.0 & 1.0 & 2.0 & 2.0 & 2.5 & 2.4 & 3.0 & 2.4 & 2.12 & 1.95 & 20.0 \\
\hline main & CP-3443 & 1.2 & 1.0 & 2.3 & 2.0 & 2.4 & 2.3 & 2.4 & 2.3 & 2.07 & 1.90 & 4.2 \\
\hline & CP-4105 & 1.2 & 1.1 & 2.1 & 1.8 & 2.8 & 2.3 & 3.2 & 2.2 & 2.32 & 1.85 & 31.3 \\
\hline Mean & & & & & & & & & & & & \\
\hline $\mathrm{LSD}^{\#}$ & & $0.02^{* * *}$ & $0.01^{* * *}$ & $0.04 * *$ & $0.03 * *$ & $0.05^{* *}$ & $0.03^{\text {*** }}$ & $0.04^{* *}$ & $0.04 * *$ & & & \\
\hline $\mathrm{C} \times \mathrm{T}$ & & & & & & & & & & & & \\
\hline & CP-3486 & 15.2 & 15.0 & 30.4 & 36.4 & 39.2 & 50.2 & 56.0 & 67.9 & 35.2 & 42.37 & 21.3 \\
\hline Number & CP-4069 & 15.7 & 15.9 & 25.7 & 29.3 & 36.1 & 45.8 & 51.7 & 59.7 & 32.3 & 37.67 & 15.5 \\
\hline o1 & CP-3443 & 15.0 & 14.8 & 24.5 & 28.5 & 33.1 & 47.1 & 50.6 & 63.0 & 30.8 & 38.35 & 24.5 \\
\hline & CP-4105 & 16.1 & 15.7 & 32.2 & 38.6 & 40.6 & 57.6 & 58.7 & 71.5 & 36.9 & 45.85 & 21.8 \\
\hline Mean & & & & & & & & & & & & \\
\hline $\mathrm{LSD}^{\#}$ & & $0.31^{*}$ & NS & $0.65^{* *}$ & $0.46^{* *}$ & $0.88^{* *}$ & $0.62^{* *}$ & $1.67^{* *}$ & $1.61^{* *}$ & & & \\
\hline $\mathrm{C} \times \mathrm{T}^{\$}$ & & & & & & & & & & & & \\
\hline & CP-3486 & 0.8 & 0.7 & 0.9 & 0.6 & 1.0 & 0.7 & 0.9 & 0.6 & 0.9 & 0.65 & 33.3 \\
\hline Chl-a & CP-4069 & 0.9 & 0.6 & 1.0 & 0.6 & 0.9 & 0.8 & 0.7 & 0.5 & 0.87 & 0.62 & 28.6 \\
\hline$(\mathrm{mg} / \mathrm{g}$ & CP-3443 & 0.9 & 0.8 & 1.1 & 1.0 & 1.2 & 1.0 & 1.1 & 1.0 & 1.07 & 0.95 & 9.10 \\
\hline & CP-4105 & 0.9 & 0.8 & 1.0 & 0.8 & 1.1 & 0.8 & 1.0 & 0.8 & 1.0 & 0.80 & 20.0 \\
\hline Mean & & & & & & & & & & & & \\
\hline $\mathrm{LSD}^{\#}$ & & $0.02 * *$ & $0.01 * *$ & $0.02 * *$ & $0.01 * *$ & $0.02 * *$ & $0.02 * *$ & $0.01 * *$ & $0.01 * *$ & & & \\
\hline $\mathrm{C} \times \mathrm{T}^{\$}$ & & & & & & & & & & & & \\
\hline & CP-3486 & 0.4 & 0.3 & 0.5 & 0.4 & 0.5 & 0.3 & 0.4 & 0.3 & 0.45 & 0.32 & 25.0 \\
\hline Chl-b & CP-4069 & 0.3 & 0.1 & 0.4 & 0.2 & 0.5 & 0.2 & 0.4 & 0.2 & 0.4 & 0.17 & 50.0 \\
\hline (mg/g & CP-3443 & 0.4 & 0.3 & 0.4 & 0.3 & 0.4 & 0.4 & 0.4 & 0.3 & 0.4 & 0.32 & 25.0 \\
\hline & CP-4105 & 0.4 & 0.4 & 0.5 & 0.4 & 0.4 & 0.2 & 0.4 & 0.3 & 0.42 & 0.32 & 25.0 \\
\hline Mean & & & & & & & & & & & & \\
\hline $\mathrm{LSD}^{\#}$ & & $0.006^{*}$ & $0.005^{*}$ & $0.007^{*}$ & $0.005^{*}$ & $0.006^{*}$ & $0.005^{*}$ & $0.007 *$ & $0.005^{*}$ & & & \\
\hline $\mathrm{C} \times \mathrm{T}^{\mathrm{S}}$ & & & & & & & & & & & & \\
\hline Total & CP-3486 & 1.2 & 1.0 & 1.4 & 1.0 & 1.5 & 1.0 & 1.3 & 0.9 & 1.35 & 0.97 & 30.8 \\
\hline Chl & CP-4069 & 1.2 & 0.7 & 1.4 & 0.8 & 1.4 & 1.0 & 1.1 & 0.7 & 1.27 & 0.80 & 36.4 \\
\hline$(\mathrm{mg} / \mathrm{g}$ & CP-3443 & 1.3 & 1.1 & 1.5 & 1.3 & 1.6 & 1.4 & 1.5 & 1.3 & 1.47 & 1.27 & 13.3 \\
\hline FW) & CP-4105 & 1.3 & 1.2 & 1.5 & 1.2 & 1.5 & 1.0 & 1.4 & 1.1 & 1.42 & 1.12 & 21.4 \\
\hline Mean & & & & & & & & & & & & \\
\hline LSD $^{\#}$ & & $0.025^{*}$ & $0.018^{*}$ & $0.019^{*}$ & $0.013^{*}$ & $0.027^{*}$ & $0.019^{*}$ & $0.026^{*}$ & $0.018^{*}$ & & & \\
\hline $\mathrm{C} \times \mathrm{T}^{\$}$ & & & & & & & & & & & & \\
\hline & CP-3486 & 1.2 & 0.8 & 1.5 & 1.2 & 1.8 & 1.4 & 1.3 & 1.0 & 1.45 & 1.1 & 23.1 \\
\hline POD & CP-4069 & 1.7 & 1.0 & 2.0 & 1.5 & 2.3 & 1.7 & 1.7 & 1.5 & 1.92 & 1.42 & 11.8 \\
\hline$\left(\begin{array}{ll}\text { ODI } / \\
\min / \mathrm{mos}\end{array}\right.$ & CP-3443 & 1.4 & 0.9 & 1.7 & 1.4 & 2.0 & 1.8 & 1.4 & 1.3 & 1.62 & 1.35 & 7.10 \\
\hline & CP-4105 & 1.1 & 0.7 & 1.4 & 1.1 & 1.7 & 1.3 & 1.3 & 1.1 & 1.37 & 1.05 & 15.4 \\
\hline Mean & & & & & & & & & & & & \\
\hline $\mathrm{LSD}^{\#}$ & & $0.025^{*}$ & $0.018^{*}$ & $0.031^{*}$ & $0.022 *$ & $0.034^{*}$ & $0.024^{*}$ & $0.027^{*}$ & $0.019^{*}$ & & & \\
\hline $\mathrm{C} \times \mathrm{T}^{\mathrm{S}}$ & & & & & & & & & & & & \\
\hline
\end{tabular}

\# - least significant difference $(\mathrm{P}=0.05)$ for Fe-sufficient and Fe-deficient soils individually, $\$=$ common least significant difference for both Fesufficient and Fe-deficient soils for treatment comparisons, $\mathrm{C}-$ Fe-sufficient soil, $\mathrm{T}-$ Fe-deficient soil, LSD - Least significant difference ( $\mathrm{P}=0.05)$, ** - highly significant, * - significant, Change (\%) - \% change for mean across four stages between Fe-sufficient and Fe-deficient soils. 
may have been due to low activation and/or a reduced production of the POD enzyme. In comparison between genotypes, maximum peroxidase activity was noted in CP-3443 followed by CP-4105, CP-3486 and CP-4069 under Fe-deficient soils (Table 2). This implies during redox homeostasis, the antioxidant system in tolerant genotypes maintains a balance between production and scavenging of reactive oxygen species (ROS); such a balance is critical for the protection of the system against oxidative burst (Balakrishnan, 2000).

\section{Yield components}

Under Fe-deficient soil, reduced yield was observed in all genotypes compared to plants grown under Fesufficient soil. However, IDC tolerant genotype were found to have better yield and its related traits compared to susceptible genotypes. The decrease in yield under Fe-deficient soil being up to $16 \%$ in $\mathrm{CP}$ 3443, followed by CP-4105 (20\%), CP-3486 (27\%) and CP-4069 (28\%) of its potential yield under Fesufficient (Fig. 1a). Similarly, reduced in number of tubers per plant (13-19\%) and average tuber weight (3-12\%) were recorded in all four genotypes (Fig. 1b $\&$ c). Under Fe-deficient soil, tolerant genotypes have better photosynthetic activity as shown by higher number of leaves and chlorophyll content while registered minimum reduction in number of tubers, average tuber weight and overall yield of plants as compared to susceptible genotypes.

Root architecture plays an important role in Fe uptake. Previous studies (Zou et al., 2013; Li et al., 2015) have shown that most species allocate more biomass to roots at reduced availability of $\mathrm{Fe}$ and allocate root biomass in shallow soil horizons, as well as increase root length and grow more and more root hairs and lateral roots; some also produce cluster roots, thereby promoting Fe uptake. Root-shoot ratio is the quantity of plant tissue that supports the quantity of those with growth functions. In case of root to shoot ratio an increase (15\%) was observed in tolerant genotypes (CP-3443). A slight reduction of 3\% was noted in medium tolerant genotype (CP-4105), whereas a reduction of $8 \%$ and $17 \%$ was observed in $\mathrm{CP}-3486$ and CP-4069, respectively under Fe-deficient soil (Fig. 1d). Dry matter partitioning to different plant parts was significantly influenced both Fe-sufficient and Fe- deficient conditions. In the study, tolerant genotypes have more root biomass compared to susceptible genotypes. This may be due to better and deeper root system in the genotypes which help in absorption of nutrient from the deeper and surrounding layer of the soils. Root to shoot ratio clearly exhibit significant difference amongst potato genotypes in both the conditions. Genotypes with a higher root biomass actually compete more effectively for soil nutrients with the ability to produce higher yields, particularly under stress conditions. This is supported by the significant relationship of root to shoot ratio with yield (Table 3).

The available nutrient status of the soil is another important property which support the crop growth while, the crop growth and dry matter accumulation depends upon the ability of the soil to supply nutrients, the nutrients release from the soil in turn depends upon the demand from growing plants. Micronutrients, in particular $\mathrm{Fe}$ and $\mathrm{Zn}$, either function as metal components of different enzymes or as functional structural or regulatory cofactors and are therefore connected to photosynthesis and protein synthesis. The concentration of $\mathrm{Fe}$ and $\mathrm{Zn}$ were estimated in the tubers to know their accumulation. A decrease in concentration of $\mathrm{Fe}$ ranges from 7.17 to $12.33 \%$ in tubers was observed in all the genotypes under Fedeficient soil (Fig. 1e). This may be attributed to low expression of genes resulting in low xylem mobility and poor translocation capacity under Fe-deficient soil condition. A similar trend was observed in $\mathrm{Zn}$, a stimulator under Fe-deficient conditions (6.54-10.05\%; Fig. 1f)

\section{Associations}

A significant positive correlation was observed between morpho-physiological, biochemical and yield parameters in the study (Table 3 ). Number of leaves showed significant $(\mathrm{P}<0.05)$ and positive correlation with parameters like total chlorophyll (0.981) and yield (0.970). While, yield per plant was also highly significant with number of tubers (0.957) and root to shoot ratio (0.973), respectively (Table 3). Under Fe-deficient condition, the genotype CP-3443 was able to produce more leaves which participated directly or indirectly in the manufacturing of more chlorophyll (Boamponsem et al., 2017). Further, their leaves function as efficient photosynthesis structures and 


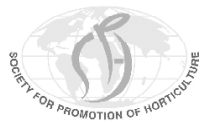

Challam et al

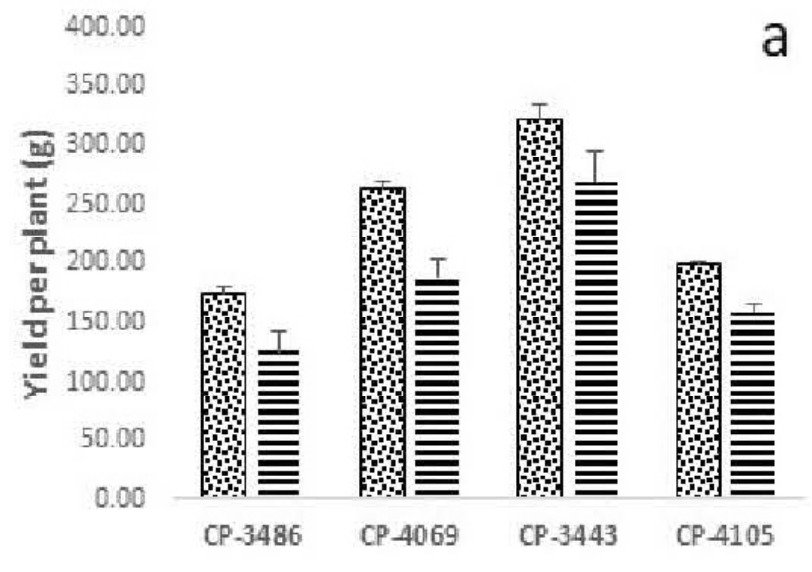

a 14

b
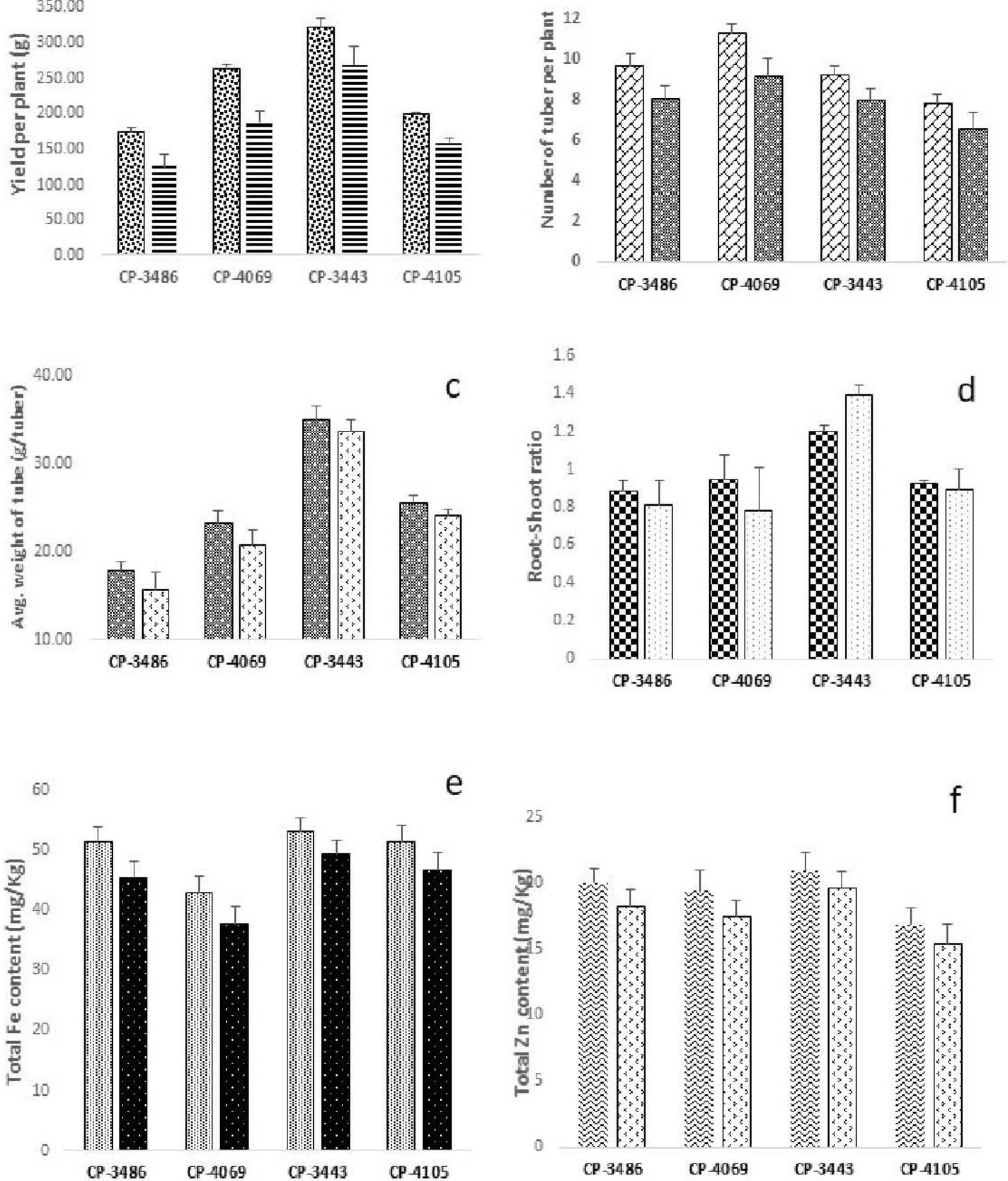

25

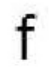

Fig. 1: Difference among IDC resistant and susceptible potato genotypes under normal and calcareous Fe soils for yield and its component traits a) Yield, b) Number of tubers, c) Avg. weight of tuber, d) Root-Shoot ratio, e) Total Fe content, f) Total $\mathrm{Zn}$ content. Mean of tolerant and susceptible genotypes considered for comparison; Standard error bar is common for both resistant and susceptible genotypes. 
Chlorosis resistance to iron deficiency and their effect on yield and related attributes in potato

Table 3: Association between mean of morpho-physiological and biochemical parameters across all four stages and yield -related traits

\begin{tabular}{|l|l|l|l|l|l|l|l|l|l|}
\hline & PH & TMS & NL & TC & POD & Yield & No.Tub & Wt.Tub & R:S \\
\hline PH & 1 & & & & & & & & \\
\hline TMS & 0.913 & 1 & & & & & & & \\
\hline NL & -0.542 & -0.156 & 1 & & & & & & \\
\hline TC & -0.461 & -0.059 & $.981^{*}$ & 1 & & & & & \\
\hline POD & -0.027 & 0.366 & 0.765 & 0.867 & 1 & & & & \\
\hline Yield & -0.352 & 0.06 & $.970^{*}$ & $.991^{*}$ & 0.895 & 1 & & & \\
\hline No.Tub & -0.358 & 0.039 & 0.9 & $.967^{*}$ & 0.943 & $.957^{*}$ & 1 & & \\
\hline Wt.Tub & -0.914 & -0.807 & 0.497 & 0.494 & 0.208 & 0.376 & 0.494 & 1 & \\
\hline R:S & -0.136 & 0.28 & 0.888 & 0.942 & $.962^{*}$ & $.973^{*}$ & 0.947 & 0.21 & 1 \\
\hline
\end{tabular}

PH-plant height, TMS-total main stems, NL-number of leaves, TC-total chlorophyll, POD-peroxidase, No.Tub-number of tubers, Wt.Tub-weight of tubers, R:S-root-to-shoot ratio

* Correlation is significant at $\mathbf{P}$ value $=0.05 * *$ Correlation is significant at $\mathbf{P}$ value $=0.01$

produced higher amount of carbohydrates in the plant system registering minimum reduction in number of tubers and overall yield of plants compared to susceptible genotypes (Braun et al., 2016). While the root-shoot ratio indicates that the tolerant genotypes may have efficient root to shoot transport and redistribution of $\mathrm{Fe}$ in the plant $(\mathrm{Xu}$ et al., 2017). This positive correlation further confirms the involvement of $\mathrm{Fe}$ in increasing the photosynthetic apparatus and maintaining the minimal stress in tolerant genotypes to enhance the physiological process under Fe-deficient soils.

\section{CONCLUSION}

Under Fe-deficient soil conditions, IDC tolerant genotypes recorded a significantly higher chlorophyll, and peroxidase activity in leaves across all four crop growth stages compared to susceptible genotypes confirming their utility as traits for identification and development of IDC tolerant potato genotypes. Towards developing high-yielding, IDC tolerant potato cultivars for Fedeficient environments, selection may be practiced for higher tuber weight and root to shoot ratio.

\section{REFERENCES}

Aliche, E.B., Bourke, A. P., Sanchez, M. R., Oortwijn, M., Gerkema, E. d., As, H. V., Visser, R.G.F., and van der Linden, C. G. 2020. Morphological and physiological responses of the potato stem transport tissues to dehydration stress. Planta, 251: 45 .

Balakrishnan, K. 2000. Peroxidase activity as an indicator of the iron deficiency in banana. Ind. J. Plant Physi., 5(4): 389-391.

Boamponsem, G. A., Leung, D.W.M., Lister, C. 2017. Insights into resistance to Fe deficiency stress from a comparative study of in vitro-selected novel Fe-efficient and Fe-inefficient potato Plants. Front. Plant Sci., 8:1581.
Boodi, I. H., Pattanashetti, S. K., Biradar, B. D., Naidu, G. K., Chimmad, V. P., Kanatti, A. and Debnath. M.K. 2016. Morpho-physiological parameters associated with iron deficiency chlorosis resistance and their effect on yield and its related traits in groundnut. J. Crop Sci. Biotechnol., 19(2): 177-187.

Braun, H., Fontes, P. C. R., Silva., Finger, T. P., Fernando L., Cecon, P. R., Ferreira, A. P. S. 2016. Carbohydrates Concentration in leaves of potato plants affected by nitrogen fertilization rates. Revista Ceres., 63(2) : 241-248.

Chatterjee, C., Gopal, R. and Dube, B. K. 2006. Impact of iron stress on biomass, yield, 
metabolism and quality of potato (Solanum tuberosum L.). Sci. Hort., 108:119-140.

Challam, C., Dutt, S., Sharma, J., Bag, T.K., Raveendran, M. and Sudhakar, D. 2021. Screening for iron deficient chlorosis (IDC) tolerant genotypes in potato (Solanum tuberosum, L.) under aeroponic system. Asian J. Microbiol. Biotechnol. Environ. Sci., 23(1): 92-99.

FAO Stat, FAO Stat accessed vide http:// www.fao.org/faostat/en/\#data/QC on 12/8/2019

Kalra, Y. P. 1988. Handbook of Methods for Plant Analysis. Boca Raton: CRC press

Li, G. J., H. Song, B. Li, H. J. Kronzucker, and W. M. Shi. 2015. Auxin resistant 1 and PINFORMED2 protect lateral root formation in Arabidopsis under iron stress. Plant Physiology 169: 2608-2623.

Li-Xuan, R., Yuan-Mei, Z., Rong-Feng, J. and Fu-Suo. Z. 2005. Mechanisms of bicarbonate induced iron-deficiency chlorosis of peanut on calcareous soils. Acta Ecol. Sinica., 4:795-801

M'sehli, W., Houmani, H., Donninic, S., Zocchi, G., Abdelly, C. and Gharsalli. M. 2014. Iron deficiency tolerance at leaf level in Medicago ciliaris plants. Am. J. Plant Sci., 5: 2541- 2553.

Mahender, A., Swamy, B.P.M., Anandan, A., Ali, J. 2019. Tolerance of iron-deficient and -toxic soil conditions in rice. Plants, 8(2): 31

Samdur, M.Y., Singh, A. L., Mathur, R. K., Manivel, P., Chikani, B. M., Gor, H. K. and. Khan, M. A. 2000. Field evaluation of chlorophyll meter for screening groundnut (Arachis hypogaea L.) genotypes tolerant to iron-deficiency chlorosis. Cur. Sci., 79(2): 211-214.

Samdur, M.Y., Mathur, R. K., Manivel, P., Singh, A. L., Bandyopadhyay, A. and Chikani. B.M. 1999. Screening of some advanced breeding lines of groundnut (Arachis hypogaea) for tolerance of lime-induced iron-deficiency chlorosis. Indian J. Agri. Sci., 69(10):722-725.

Simko, I., Van Den Berg, J. H., Vreugdenhil, D. and Ewing. E. E. 2008. Mapping loci for chlorosis associated with chlorophyll b deficiency in potato. Euphytica, 162:99-107.

Singh, M. V. 2009. Micronutrient nutritional problems in soils of India and improvement for human and animal health. Indian J. Fertil., 5: 11-56

Singh, M., Chaudhary, S. R., Sharma S. R. and Rathore. M. S. 2004. Effect of some micronutrients on content and uptake by chickpea (Cicer arietinum). Agri. Sci. Dig., 24(4): 268-270.

Terry, N. and J. Abadia. 1986. Function of iron in chloroplasts. J. Plant Nutr., 9(3):609-646.

Xu, J. Q., Chen, X. L. and Yu, F. T.017. Effects of BPDS-Fe(a!) on the difference in tolerance to iron deficiency of maize seedlings under different ammonium/nitrate ratios. Sci. Agr. Sinica., 50: 1223-1233.

Zou, N., Li, B. H., Chen, H., Su, Y. H. H., Kronzucker, J. and Xiong. L. M. 2013. GSA-1/ARG1 protects root gravitropism in Arabidopsis under ammonium stress. New Phytolo., 97-111.

(Received on 31.03.2021, Revised on 14.04.2021, Accepted on 19.05.2021) 